\title{
Ética e Investigação Científıca: do Exórdio ao Desenvolvimento aplicado na Pesquisa com Crianças
}

\author{
Ethics and Scientific Research: from the exordium to the development \\ applied in research with children
}

1 Mariana Kehl marianakehl@gmail.com

1 Graduada em Psicologia pela Universidade do Estado do Rio de Janeiro (2015) com período sanduíche na Eberhard Karls Universität Tübingen (2013/2014 - Alemanha) através de financiamento da Coordenação de Aperfeiçoamento de Pessoal de Nível Superior (CAPES) e apoio do Serviço Alemão de Intercâmbio Acadêmico (DAAD). É aluna do Programa de Mestrado em Psicologia Clínica da Pontifícia Universidade Católica do Rio de Janeiro (PUC-Rio) na qualidade de bolsista CAPES com período sanduíche na Universidade Autónoma de Madrid (Espanha) financiado pelo programa de mobilidade UAM-Banco Santander/CEAL.

\section{Resumo}

A Resolução 196/96, instituída pelo Conselho Nacional de Saúde, apresenta uma série de normas e diretrizes, no que concerne à realização de pesquisas envolvendo seres humanos. Diferentes campos do conhecimento devem lidar com seus desdobramentos e muitas discussões, reações e polêmicas emergem desse impacto. 0 presente artigo pretende, por meio de uma breve revisão bibliográfica, discorrer acerca dos efeitos precípuos dessa resolução no âmbito das Ciências Humanas, bem como outras questões pertinentes à ética e suas vicissitudes, no que se refere às práticas de pesquisa com crianças, abordando, outrossim, seus aspectos teórico-metodológicos.

\section{Palavras-chave}

Resolução 196/96; ética; Ciências Humanas; pesquisa com crianças.

\begin{abstract}
Resolution 196/96 established by the National Council of Health presents a succession of precepts and guidelines regarding the conduction of research involving human subjects. Different fields of knowledge must deal with its consequences and many discussions, reactions and controversies emerge from this impact. This article intends through a concise literature review to discuss the foremost effects of this resolution in the context of the Human Sciences as well as other issues pertaining to ethics and its vicissitudes concerning to research practices with children, addressing, moreover, its theoretical and methodological aspects.
\end{abstract}

\section{Keywords}

Resolution 196/06; Ethics; Human Science; Research with Children.

\section{Como você deve citar?}

KEHL, Mariana. Ética e Investigação Científica: do Exórdio ao Desenvolvimento aplicado na Pesquisa com Crianças. Cadernos UniFOA, Volta Redonda, n. 32, p. 47-54, dez. 2016. 


\section{INTRODUÇÃO}

A Resolução 196/96, instituída pelo Conselho Nacional de Saúde, apresenta uma série de normas e diretrizes, no que concerne à realização de pesquisas envolvendo seres humanos. Diferentes campos do conhecimento devem lidar com seus desdobramentos e muitas discussões, reações e polêmicas emergem desse impacto. 0 presente artigo pretende, por meio de uma breve revisão bibliográfica, discorrer acerca dos efeitos precípuos dessa resolução no âmbito das Ciências Humanas, bem como outras questões pertinentes à ética e suas vicissitudes, no que se refere às práticas de pesquisa com crianças, abordando, outrossim, seus aspectos teórico-metodológicos.

Este artigo foi elaborado a partir de uma pesquisa bibliográfica nas bases de dados Scielo, Pepsic e periódicos da CAPES, utilizando 18 expressões-chave ${ }^{2}$ que resultaram na obtenção de 204 artigos, dos quais 19 foram selecionados de acordo com as proposições e objetivos deste texto, que, por sua vez, fez parte de uma pesquisa mais ampla na área de Psicologia Social, em que se pretendeu investigar os sentidos de família produzidos por crianças $^{3}$.

Anteriormente ao estabelecimento de mecanismos de controle ético padronizados das práticas de pesquisa envolvendo seres humanos, a historiografia nos mostra que, por diversas vezes, houve abusos e a "cobaização do ser humano" (HOOSNE e VIERA apud ARAUJO, 2003). Um exemplo evidente pode ser encontrado ainda no século XX: o governo nazista alemão e sua política higienista de ordem médica e caráter intervencionista. Por meio da recuperação de modelos de excessos e seus correspondentes e drásticos impactos, constituiu-se como fundamental e imperativa a necessidade de se estabelecer uma padronização nos procedimentos de pesquisa com o objetivo principal de proteção, cuidado e respeito, desdobrando-se, então, numa série de direitos e deveres aos implicados.

No entanto, ainda é possível fazer ressalvas a respeito do que temos hoje como metodologia e regulamentos éticos, uma vez que há muito que se aperfeiçoar, de modo que não haja também despropósitos, descomedimentos, incoerências e inconsistências nessas regras, questões que serão articuladas a seguir.

\section{A RESOLUÇÃO 196/96}

A Resolução 196/96, sancionada em 10 de outubro de 1996, pelo Conselho Nacional de Saúde, e homologada pelo Ministério da Saúde, incorpora e direciona os cuidados éticos necessários e imprescindíveis em pesquisas com seres humanos, tecendo alguns parâmetros. Segue e agrega um conjunto "de propostas e recomendações contidas em acordos e códigos internacionais, concebidos no âmbito de instituições, como a Organização das Nações Unidas (ONU), a Organização Mundial de

2 "Consentimento informado", "Consentimento Livre", "Criança pesquisa psicologia", "Discurso criança", "Entrevista criança", "Escuta criança", "Ética criança", "Ética pesquisa", "Ética pesquisa criança", "Grupo criança", "Infância", "Método pesquisa criança", "Método pesquisa ética", "Metodologia criança", "Pesquisa com criança", "Pesquisa qualitativa", "Psicologia pesquisa ética" e "Resolução 196".

3 O título da pesquisa em questão é "Família Contemporânea na perspectiva de crianças e adolescentes". Tal proposta teve início em 2011 e foi realizada na Universidade do Estado do Rio de Janeiro (UERJ), coordenada pela Profa. Dra. Anna Paula Uziel e subsidiada pela UERJ e pela Fundação Carlos Chagas de Amparo à Pesquisa do Estado do Rio de Janeiro (FAPERJ). O projeto foi divido em dois eixos denominados: "Concepções de Família para crianças" e "Ética em pesquisa com criança; discussões metodológicas", no qual se situou a presente revisão. 
Saúde (OMS) e o Conselho para Organizações Internacionais de Ciências Médicas (Cioms, na sigla em inglês), a partir do Código de Nuremberg ${ }^{4}$, de 1947" (DUARTE, 2011).

A Resolução qualifica a pesquisa com seres humanos como "pesquisa que, individual ou coletivamente, envolva o ser humano, de forma direta ou indireta, em sua totalidade ou partes dele, incluindo o manejo de informações ou materiais". É importante destacar que a Resolução é uma recomendação e não possui força de lei, isto é, não é um mecanismo compulsório, nem há obrigatoriedade na adesão pelos pesquisadores e posterior submissão de seus projetos aos critérios que são estabelecidos. Entretanto, muitos periódicos, congressos e agências de fomento de pesquisa solicitam que os trabalhos sejam submetidos aos comitês de ética, o que intensifica o debate sobre a autonomia e responsabilidade do pesquisador e os limites de atuação de agentes externos, visto que eles não respondem em nenhuma instância por eventuais problemas que a investigação possa gerar.

A Resolução se propõe a regular procedimentos de todas as áreas do conhecimento, desde o campo biomédico até as ciências humanas, incluindo pesquisas que optam por metodologias não interventivas. De acordo com Duarte (2011), tal processo e sua correlata dinâmica trazem à tona algumas impropriedades e problemas, sobretudo, às ciências humanas, uma vez que, a priori, a regulamentação surge com a finalidade de responder a uma implicação do campo médico e suas tecnologias. Dessa forma, submetem-se duas áreas de naturezas diferentes, cada qual com suas idiossincrasias, a uma lógica comum, o que, fatalmente, traz dificuldades à produção científica das ciências humanas dentro dos preceitos éticos estabelecidos.

Além de normatizar requisitos e processos que devem ser seguidos pelos pesquisadores, a Resolução também discorre acerca de aspectos referentes à constituição e funcionamento dos Comitês de Ética em pesquisa (CEP) que, por sua vez, trata-se de um "colegiado interdisciplinar e independente [...] que deve existir nas instituições que realizam pesquisas envolvendo seres humanos no Brasil" (BRASIL, 2002). Eles se encontram subordinados à CONEP (Comissão Nacional de Ética em Pesquisa), vinculados ao Ministério da Saúde e exercem um papel consultivo, isto é, emitem seu parecer, aprovando ou não uma pesquisa, de acordo com sua adequação aos padrões presentes na resolução. Segundo o Conselho Nacional de Saúde (BRASIL, 2002, p.11), o CEP tem como missão "defender os interesses dos sujeitos da pesquisa em sua integridade e dignidade e [...] contribuir no desenvolvimento da pesquisa dentro de padrões éticos", além disso, mais que regular, o CEP deve desempenhar um papel educativo, assegurando "a formação continuada dos pesquisadores e da instituição", promovendo a "discussão dos aspectos éticos das pesquisas [...]. Dessa forma, deve promover atividades, tais como seminários, palestras, jornadas, cursos e estudos de protocolos de pesquisa".

Conforme relata Thomanik (2008, p. 397), um dos pontos críticos em relação aos CEPs diz respeito ao desempenho de seu papel educativo. A partir de sua experiência pessoal e de colegas de diferentes instituições, tem-se avaliado que sua atuação tem sido voltada "muito mais para a verificação sistemática do cumprimento de exigências burocráticas do que para a discussão de aspectos éticos ou morais dos procedimentos" propostos.

Embora muitos impasses se apresentem como desdobramentos da Resolução referente às pesquisas em ciências humanas, tal fato não implica em uma negação, subestimação ou não reconhecimento da necessidade de uma regulamentação científica e controle ético pelos pesquisadores de ciências humanas, mas sim na compreensão de que é preciso um documento mais adequado e pertinente à

4 O código de Nuremberg, criado em 1947, representa um marco na regulamentação e controle ético na pesquisa envolvendo seres humanos. É resultado das atrocidades praticadas durante a Segunda Guerra Mundial em nome da ciência e sua finalidade era "coibir toda forma de abuso e crueldade, toda finalidade política ou eugênica, preservando os interesses da pessoa sobre os da ciência" (POLIT e HUNGLER apud PADILHA et al, 2005). 
área. Esse fato foi explicitamente reconhecido na Resolução 466/2012 do Conselho Nacional de Saúde, que atualizou a resolução 196/96 e na qual se pode ler em seu artigo XIII.3: "As especificidades éticas das pesquisas nas ciências sociais e humanas e de outras que se utilizam de metodologias próprias dessas áreas serão contempladas em resolução complementar, dadas suas particularidades".

Assim, ao longo do ano de 2015, por iniciativa de várias Associações de Pesquisa na Área de Ciências Humanas, reunidas no Fórum de Associações de Ciências Humanas, Sociais e Sociais Aplicadas, foram recolhidas sugestões da comunidade acadêmicas que resultaram em uma nova diretriz, específica para as pesquisas em ciências humanas, a resolução 510/2016, que altera, entre outras coisas, termos por meio dos quais são estabelecidas as relações entre os pesquisadores e os participantes da pesquisa.

\section{TERMO DE CONSENTIMENTO LIVRE E ESCLARECIDO}

A Resolução 519/16 entende, a exemplo das anteriores, que a concordância dos sujeitos em participar de uma pesquisa deve ser claramente explicitada. Nesse sentido, propõe o Consentimento Livre e Esclarecido como "anuência do participante da pesquisa ou de seu representante legal, livre de simulação, fraude, erro ou intimidação, após esclarecimento sobre a natureza da pesquisa, sua justificativa, seus objetivos, métodos, potenciais benefícios e riscos" e por sua aceitação não apenas nacional, mas internacional, o TCLE assim definido é entendido como um documento essencial para uma conduta ética, representando respeito à autonomia do sujeito.

No entanto, se limitado a isso, o TCLE e a exigência de sua obtenção formal, também se apresentam como impasses para as pesquisas na área de ciências humanas. Nessas condições, Duarte (2011) o entende como totalmente despropositado na aplicação em pesquisas não experimentais e/ ou interventivas, uma vez que, para a antropologia, por exemplo, que encontra seus sujeitos em situação "dominadas, minoritárias, carentes ou marginais", o termo pode tornar a pesquisa inviável. Em sujeitos que se encontram em situações ilegais, de corrupção, clandestinas e até culturalmente díspar (como população rural, indígena e analfabeta), a exigência da assinatura de um documento se torna problemática e assim, a pesquisa perde sua viabilidade.

Reconhecendo isso, a resolução 519/16 avança ao definir formas diversas, por meio das quais se podem dar a comunicação entre pesquisadores e sujeitos da pesquisa, tanto para esclarecê-los quanto para obter seu consentimento. "Esclarecimento" é então definido nos seguintes termos:

\footnotetext{
processo de apresentação clara e acessível da natureza da pesquisa, sua justificativa, seus objetivos, métodos, potenciais benefícios e riscos, concebido na medida da compreensão do participante, a partir de suas características individuais, sociais, econômicas e culturais, e em razão das abordagens metodológicas aplicadas. Todos esses elementos determinam se o esclarecimento dar-se-á por documento escrito, por imagem ou de forma oral, registrada ou sem registro.
}

Além disso, admite a possiblidade, devidamente justificada, de se dispensar a exigência de TCLE, quando os resultados da pesquisa forem suscetíveis de contaminação ao serem anunciados seus objetivos ou quando a obtenção de consentimento exponha os sujeitos a riscos, estigmas ou quaisquer formas de discriminação. No entanto, a alteração mais significativa, diante dos objetivos do presente artigo, é a que diferencia "Consentimento Livre e Esclarecido" de "Assentimento livre e esclarecido", este último relativo a pesquisas com crianças, como se verá a seguir. 


\section{PESQUISA COM CRIANÇAS}

Embora não sejam tão recentes as discussões consequentes das regulações éticas em pesquisas, há muito a se desenvolver e discutir em relação à pesquisa com crianças. É preciso, também, que algumas considerações sejam feitas: é necessário que o referencial teórico utilizado a compreenda a partir de um estatuto de sujeito ativo, isto é, como "ator social e como produtora de cultura e de significados" (MÜLLER e HASSEN, 2009), quando se fala em pesquisa na área de ciências humanas e sociais. Já a área da saúde que, majoritariamente, concebe a criança a partir da ideia de "um ser incapaz para discernir, dadas suas limitações de compreensão" (SIGAUD et al., 2009), tem o processo de garantia de voluntariedade previsto na Resolução 196/96, transformado em requisito particularmente problemático. Não se pretende discutir o nível de procedência das deliberações infantis, mas seu entendimento como sujeito de voz ativa.

A perspectiva sobre a infância e seus sujeitos como atores sociais está presente na maioria dos artigos utilizados na revisão bibliográfica, entretanto, tal posicionamento é problematizado e se questiona se, de fato, essa ideia se efetiva nas práticas de pesquisa, uma vez que ainda hoje algumas teorias associam a infância a uma fase de imaturidade e irracionalidade (MÜLLER e HASSEN, 2009) e daí o porquê de Müller e Hassen (2009) a entenderem como um "fenômeno híbrido", constituindo-se, então, um paradoxo do mundo contemporâneo. $O$ entendimento de infância e seus sujeitos sofreu uma série de modificações ao longo do tempo (ARIÉS, 1978). A criança como sujeito da história e cultura é uma concepção em processo (KRAMER, 2002, p.43)

Muitos autores, ao trabalhar com crianças e infância, trazem em seus discursos o modo como sua concepção foi construída historicamente e, sem exceção, entendem a infância como um fenômeno próprio de um campo multidisciplinar, embora o desenvolvimento dos estudos tenha se dado principalmente no campo da Psicologia e Pedagogia. (MÜLLER e HASSEN, 2009)

Qvortrup (2010) e Kramer (2002) trazem um aspecto importante sobre a necessidade de proteção, ainda que se entenda a criança como sujeito de voz e produtora de cultura. Embora seja imprescindível uma série de mecanismos de proteção como descreverei mais adiante, é preciso cuidado para não se entender que, por haver uma demanda de cuidado, seja necessário deixá-las à margem, fora da sociedade.

\section{PROCEDIMENTOS: TÉCNICAS E CUIDADOS ÉTICOS}

A maioria dos autores consultados entende que é essencial para o pesquisador uma conduta que garanta a participação voluntária das crianças na pesquisa, embora nem sempre tenha sido assim. Sigaud et al. (2009) relatam que, até o início do século XX, muitas crianças eram envolvidas em processos de pesquisa sem que qualquer tipo de conduta ética fosse adotada, justificando, muitas vezes, que a escolha dos sujeitos se dava "dado o alto custo dos animais" (KIPPER e GOLDIM apud SIGAUD et al., 2009, p. 1343). Quando tais condutas vieram à tona, muitos países passaram a impedir a realização de pesquisas com crianças.

Um ponto extremamente sensível é a discussão a respeito da capacidade de compreensão e decisão de uma criança ao optar em participar de uma pesquisa. Encontramos no corpo textual da Resolução 510/2016 a seguinte definição de "Assentimento Livre e Esclarecido": 
Anuência do participante da pesquisa - criança, adolescente ou indivíduos impedidos de forma temporária ou não de consentir, na medida de sua compreensão e respeitadas suas singularidades, após esclarecimento sobre a natureza da pesquisa, justificativa, objetivos, métodos, potenciais benefícios e riscos. A obtenção do assentimento não elimina a necessidade do consentimento do responsável.

Assim, fica entendido que, embora os responsáveis legais possam consentir a respeito da participação de seus tutelados na pesquisa, é imprescindível que o próprio sujeito seja informado sobre todos os aspectos do trabalho de acordo com sua capacidade de entendimento, isto é, "o processo do consentimento informado demanda envolvimento mais ativos desses sujeitos, com vistas a expressar seu desejo fidedigno e não se restringe a manifestação do responsável" (SIGAUD et al., 2009). Tal entendimento está em consonância com a concepção da criança como sujeito de direitos e também como sujeito que deve ser protegido, conforme estabelecido pelo Estatuto da Criança e Adolescente.

Contudo, a disponibilidade da informação não implica, obrigatoriamente, em um consentimento esclarecido. Sigaud et al. (2009) compreendem o consentimento como algo "baseado na capacidade da pessoa de receber informações e atribuir-Ihes significado" e, embora os termos devam ser inteligíveis pelo sujeito participante, encontramos seu texto determinado por um grupo social composto de agentes que possuem domínio da norma culta, capacidade de razão abstrata e formação acadêmica avançada, gerando disparidades e a não inteligibilidade entre aqueles que produzem o que se quer fazer entender e aqueles que devem compreender o que é dito. Como corolário, os estudos empíricos, como os de Miranda et al. (2009) e Biondo-Simões et al. (2007), demonstram que há uma incompatibilidade entre a proposta original do termo, em 1996, e seus efeitos práticos, pois até mesmo adultos podem ser induzidos ao consentimento sem que haja pleno controle e entendimento acerca de sua deliberação.

Pode se entender, então, de acordo com Sigaud et al. (2009), que respeitar os princípios éticos em pesquisas envolvendo crianças significa disponibilizar as informações em uma linguagem acessível, respeitando sua expressão de vontade e individualidade, além do consentimento do responsável e uma estratégia de abordagem que considere, ininterruptamente, suas necessidades e particularidades. Sendo assim, há um avanço claro nos termos estabelecidos pela resolução 510/2016, não apenas para as ciências humanas, mas para a pesquisa quando há a implicação e comprometimento de crianças. Um conhecimento prévio a respeito do desenvolvimento infantil e cognitivo também se mostra importante, para que sejam evitados danos à criança (NEIVA-SILVA et al, 2006), uma vez que as diferentes idades e níveis cognitivos exigem diferentes procedimentos.

É fundamental que, no primeiro contato, se construa vínculo e confiança entre a criança e o pesquisador (NEIVA-SILVA et al., 2005). 0 pesquisador deve adotar "atitudes de empatia, autenticidade e congruência [...] precisa esforçar-se para transmitir à criança sua real intenção e manifestar sua gratidão, explicitamente, ao final do procedimento", ademais, é preciso muita atenção para evitar qualquer tipo de coerção, uma vez que "o adulto frente à criança é percebido como mais poderoso [...] ele deve evitar reproduzir comportamentos que podem caracterizar dominação e adotar meios de favorecer a livre expressão da vontade infantil, criando condições atraentes que estimulem sua participação e minimizem desconforto, tais como abordar a criança em seu ambiente, na presença de pessoas de sua confiança e oferecendo claramente a possibilidade de recusa". (SIGAUD et al., 2009, p. 1344)

Os autores recomendam que a coleta de dados seja realizada em um ambiente familiar à criança, registrando que a disponibilidade de brinquedos pode facilitar o processo além de funcionar como procedimento técnico. A brincadeira como metodologia é entendida como "pré-requisito para o desenvolvimento saudável" e maneira de "elaborar o momento específico que vive", isto é, "meio de comunicação que ela possui para expressar seus sentimentos, suas ansiedades e suas frustrações" (LEMOS et al., 2009) constituindo então, uma excelente forma de ajudar a entender o que pensam e possibilitar o acesso a esse conteúdo. 
Outro aspecto relevante também se apresenta quando se discute a questão da confidencialidade/ autoria trazida por Neiva-Silva et al. (2006) e Kramer (2002) na pesquisa com crianças. Fica claro a partir de todos os procedimentos éticos documentados e sugeridos que a concepção de infância adotada a entende como sujeito de direitos e, portanto, detentora de uma identidade. Mesmo tendo seu anonimato e confidencialidade das informações garantidos por uma obrigação legal, a decisão de identificá-la mediante autorização do responsável, entendimento próprio e posterior anuência, é um aspecto a ser pensado. Sigaud et al. (2009) entendem que a criança se sente valorizada ao aceitar participar de uma pesquisa e ter seu nome real publicado, uma forma de reconhecimento de sua participação e incentivo à autonomia. Entretanto, é preciso ponderar primeiramente sobre sua proteção e futuras repercussões.

Neiva-Silva et al. (2006) discutem o dilema da confidencialidade a partir de crianças e adolescentes em situação de risco. Além da dificuldade que se apresenta, muitas vezes, para se conseguir o Termo de consentimento livre e esclarecido, o principal fator que emerge é o que fazer com informações que apontam para um alto nível de risco ou sofrimento desses sujeitos. Mesmo que o sigilo seja garantido, a proteção integral se coloca em primeiro lugar e, assim, "a quebra da confidencialidade é admitida eticamente" (NEIVA-SILVA et al., 2006).

\section{CONSIDERAÇÕES FINAIS}

Ainda que se trate de uma recomendação, as Resoluções do CNS acerca da pesquisa envolvendo seres humanos vêm sendo cada vez mais requerida por agentes externos e relevantes à produção científica. É conveniente que se observe que a finalidade desses mecanismos postos em códigos, bem como a Bioética, não é reprimir nem limitar os estudos envolvendo seres humanos, mas um movimento na tentativa de se construir uma conduta ética, protetiva e garantidora dos direitos e da dignidade humana. Embora seja possível também concluir que os esforços, nesse sentido, não têm sido plenamente satisfatórios, exigindo reformulações contínuas e diálogos entre diferentes campos de saber e entre a comunidade científica e a sociedade.

Segundo Neiva-Silva et al. (2006), é preciso que sejam discutidos e trazidos à cena os dilemas e fragilidades que os profissionais enfrentam na busca de uma conduta ética: abertura crítica e exposição deveriam figurar na ordem do dia. É preciso que os pesquisadores se sintam apoiados. As ações educativas previstas na Resolução pelos CEP seriam uma excelente maneira de se divulgar, subsidiar e também incentivar a produção e desenvolvimento da ética.

De acordo com Araujo (2003), observar simplesmente as leis, normas, regulamentações e recomendações não implica na garantia de cumprimento da eticidade de uma pesquisa. Mais que seguir procedimentos estabelecidos, é preciso um ato de "conscientizar-se" pelo pesquisador, examinando as diferenças, não homogeneizando os sujeitos e procedimentos e, principalmente, assentando em um lugar de destaque o respeito à vida. 


\section{REFERÊNCIAS}

ARAUJO, L. Z. S. Aspectos éticos da pesquisa científica. Pesquisa Odontológica Brasileira, São Paulo, v. 17 , n. 1, p. 57-63, 2003.

BRASIL. Conselho Nacional de Saúde. Diretrizes e Normas de Pesquisa em Seres Humanos. Resolução 196/96, de 09/10/96. DOU 16/10/96:21081-21085.

Ministério da Saúde. Conselho Nacional de Saúde. Manual operacional para comitês de ética em pesquisa. Brasília: Ministério da Saúde. 2002

BIONDO-SIMÕES, M. L. P; MARTYNETZ, J.; UEDA, F. M. K.; OLANDOSKI, M. Compreensão do termo de consentimento informado. Rev. Col. Bras. Cir., v.34, n.3, p.183-188, 2007.

DUARTE, L. F. D. Ética igual, pesquisas diferentes. Ciência Hoje On-line. Rio de Janeiro, abr. 2011. Disponível em: <http://cienciahoje.uol.com.br/colunas/sentidos-do-mundo/etica-igual-pesquisasdiferentes>. Acesso em: 26 Dez. 2012.

KRAMER, S. Autoria e autorização: questões éticas na pesquisa com crianças. Cadernos de Pesquisa. São Paulo, nº 116, p. 41-59, jul. 2002.

LEMOS, L. M. D.; PEREIRA, W. J.; ANDRADE, J.S.; ARAUJO, S. Vamos cuidar com brinquedos? Revista Brasileira de Enfermagem, v.63, n.6, p.950-5, 2009

MÜLLER, F.; HASSEN, M. N. A infância pesquisada. Psicologia USP, São Paulo, 20(3), jul/set. 2009.

MIRANDA, V. C.; FÊDE, A. B. S.; LERA, A. T.; UEDA, A.; ANTONANGELO, D. V.; BRUNETTI, K.; RIECHELMANN, R.; DEL GIGLIO, A. Como consentir sem entender? Revista da Associação Médica Brasileira, v.55, n.3, p.328-334, 2009.

NEIVA-SILVA, L.; LISBOA, C.; KOLLER, S. H. Bioética na pesquisa com crianças e adolescentes em situação de risco: dilemas sobre o consentimento e a confidencialidade. Jornal Brasileiro de Doenças Sexualmente Transmissíveis, v.17, n.3, p. 201-206, 2006.

PADILHA, M. I. C. S., RAMOS, F. R. S.; BORENSTEIN, C. R. A responsabilidade do pesquisador ou sobre o que dizemos acerca da ética em pesquisa. Rev Texto Contexto Enferm., v.14, n. 1, p.96-105, 2005.

QVORTRUP, J. Infância e política. Cad. Pesqui. [online]. v. 40, n. 141, pp. 777-792, 2010.

SIGAUD, C. H. S.; REZENDE, M. A.; VERÍSSIMO, M. L. O. R.; RIBEIRO, M. O.; MONTES, D. C.; PICCOLO, J.; SOUZA, J. M.; MARINS, S. S. Aspectos éticos e estratégias para a participação voluntária da criança em pesquisa. Revista da Escola de Enfermagem da USP (online), v.43, p.1342-1346, 2009.

TOMANIK, E. A. A ética e os comitês de ética em pesquisa com seres humanos. Psicologia em estudo, v.13, n.2, p.395-404, jun.,2008. 